\title{
Alexithymia Assessment and Relations with Dimensions of Personality
}

\author{
Grégoire Zimmermann ${ }^{1,2}$, Jérôme Rossier ${ }^{1}$, \\ Franz Meyer de Stadelhofen ${ }^{1}$, and François Gaillard ${ }^{1}$ \\ ${ }^{1}$ Department of Psychology, University of Lausanne, Switzerland \\ ${ }^{2}$ Institute for Psychotherapy, Department of Psychiatry, University of Lausanne, Switzerland
}

\begin{abstract}
This study examines the relationship between alexithymia, impulsiveness, locus of control, irrational beliefs, and both the domain and the facet levels of the Five-Factor Model (FFM) of personality in a sample of 136 undergraduate students by using the 26-Item and the 20-Item Toronto Alexithymia Scales (TAS-26; TAS-20), the Impulsiveness Questionnaire ( $\left.\mathrm{I}_{7}\right)$, the Internal, Powerful others, and Chance Scales (IPC), the Malouff and Schutte Belief Scale and the NEO Personality Inventory Revised. The aim of this study is to compare the TAS-26 and the TAS-20, and to explore relations between alexithymia and personality especially regarding aspects that have not been taken into account so far, like impulsiveness and irrational beliefs. As expected, alexithymia overlaps with various dimensions of the FFM, as well as other dimensions like external locus of control and irrational beliefs. Surprisingly, there is no association between alexithymia and impulsiveness. Our results suggest that alexithymia is a cognitive state of externally oriented thinking with an emotional instability associated to the inability to cope with stressful situations.
\end{abstract}

Keywords: Alexithymia, assessment, TAS, five factor model, locus of control, irrational beliefs, impulsiveness

The concept of alexithymia, literally without word for feelings, is based on observations of psychosomatic patients and was first proposed by Sifneos (1973). It is mainly characterized by a difficulty in identifying and expressing feelings, a striking paucity of fantasies, a utilitarian way of thinking (Pensée opératoire, Marty \& de M'Uzan, 1963) and a difficulty in distinguishing between feelings and physical sensations (Sifneos, 1973, 1996, 2000; Nemiah, Freyberger, \& Sifneos, 1976; Nemiah \& Sifneos, 1970). These features are thought to reflect a deficit in the cognitive processing and regulation of emotional states (Taylor, 1994). First studied in classical psychosomatic or somatic disorders, alexithymia is known today as a personality trait normally distributed in the general population; a high level of alexithymia is considered as a possible vulnerability factor for a variety of psychiatric disorders and physical illnesses (Taylor, Bagby, \& Parker, 1997; Luminet, Bagby, Taylor, \& Parker, 1999).

The assessment of alexithymia relies on clinical observations and on self-report questionnaires. In their initial studies, Taylor, Ryan, and Bagby (1985) developed the self-report Toronto Alexithymia Scale (TAS or TAS-
26) using a combined rational and empirical scale construction strategy. From a pool of 41 items representative of the substantive domain of alexithymia, 26 items were retained and clustered in four factors in accordance with the alexithymia construct: (F1) difficulty to identify and to distinguish between feelings and bodily sensations; (F2) difficulty to describe feelings; (F3) reduced daydreaming; and (F4) externally-oriented thinking. Though the TAS-26 demonstrated good psychometric properties (Bagby, Taylor, Parker, \& Loiselle, 1990), Taylor, Bagby, and Parker (1992) generated a new pool of items (26 original items and 17 additional ones) and attempted to create a revised and improved version of the scale. This effort led to the development of a 23 -item scale (TAS-R), which eliminated all items assessing daydreaming activity (Taylor et al., 1992). In contrast to the four-factor structure of the TAS-26, exploratory factor analysis of the TAS-R indicated a two-factor solution, as subsequent confirmatory factor analyses demonstrated that a three-factor structure provided a better match to the data (Taylor et al., 1997). Given this finding, Bagby, Parker, and Taylor (1994) developed a 20-item version of the scale (TAS-20) using the same 43 -item pools. The 
TAS-20 demonstrated reliability and validity, and is currently the most widely used measure of alexithymia (Taylor et al., 1997). However, by eliminating the assessment of fantasy life, the TAS-20 partially fails to measure alexithymia, as it was originally conceptualized (Sifneos, 1996, 2000).

Considerable empirical support has been demonstrated in favor of the validity of the alexithymia construct in different cultural contexts (Bressi, Taylor, Parker, Bressi, Brambilla, Aguglia, Allegranti et al., 1996; Loas, Fremaux, \& Marchand, 1995; Pandey, Mandal, Taylor, \& Parker, 1996). According to Costa and McCrae (1987), the evaluation of any new personality construct should include an examination of the relations of the construct with basic dimensions of personality.

Preliminary studies in nonclinical groups have examined relations between alexithymia and the Five-Factor Model of personality (FFM; Digman, 1990). Wise, Mann, and Shay (1992) ran stepwise multiple analyses to predict TAS-26 scores from the NEO Five Factor Inventory scales (NEO-FFI; Costa \& McCrae, 1992). In a small normal adult sample, the domains of Extraversion (26.4\%), Openness (8.3\%), and Neuroticism (3.6\%) accounted for $38.1 \%$ of the variance in TAS-26 scores. Thus, the contribution of Extraversion is important whereas the contribution of Neuroticism is surprisingly low considering that alexithymia is a vulnerability factor generally connected to emotional stability (Taylor et al., 1997).

In a convergent and discriminant validity study, Bagby, Taylor, and Parker (1994) examined correlations between the TAS-20 and the NEO Personality Inventory (NEO PI; Costa \& McCrae, 1985) domains and facets in a group of college students. As expected, the TAS-20 correlated positively with the Neuroticism dimension $(r=.27)$ and with Anxiety $(r=.25)$, Depression $(r=.36)$, Self-Consciousness (i.e., Shame and embarrassment; $r=$ $.30)$, and Vulnerability $(r=.35)$ facets. Although Extraversion did not correlate significantly with the TAS-20, one of the facets in this domain, Positive Emotion, correlated negatively $(r=-.36)$. The TAS-20 further correlated negatively and most strongly with the Openness domain $(r=-49)$ and in particular with the Fantasy $(r=$ $-.30)$, Aesthetics $(r=-.29)$, Feelings $(r=-.55)$, Actions $(r=-.24)$, and Ideas $(r=-.33)$ facets. There was no relationship with Agreeableness and Conscientiousness. These findings suggest that alexithymia is a complex construct combining elements of Neuroticism, Extraversion, and Openness.

In order to further investigate these relations, Luminet, Bagby, Wagner, Taylor, and Parker (1999) examined the relations between alexithymia and the domains and facets of the FFM by using the TAS-20 and the NEO Personality Inventory Revised (NEO PI-R; Costa \& Mc
Crae, 1992). At a dimensional level, they found similar results to those of Bagby et al. (1994) except for Extraversion. Indeed, Extraversion was associated negatively with TAS-20 scores $(r=-.36)$. At a facet level, Depression, Positive Emotions, and Feelings were the most powerful predictors of TAS-20 scores. Although alexithymia was unrelated to the dimensions of Agreeableness and Conscientiousness, at the facet level Altruism and Competence correlated negatively with TAS-20 scores.

Overall, the results of the research using the FFM support the view that alexithymia reflects individual differences in the experiencing of emotional states, which is represented by a combination of elements of the FFM, especially Neuroticism, Extraversion, and Openness. These results are consistent with clinical observations of alexithymic patients experiencing emotional instability and psychological distress (high Neuroticism), unreceptiveness to inner feelings and emotions (low Openness), and little capacity to experience positive emotions such as joy, happiness, love, and excitement (low Extraversion; Krystal, 1988; McDougall, 1982).

Taking into account theoretical considerations and clinical reports showing that alexithymic individuals manifest an externally-oriented mode of thinking and living (Marty \& Debray, 1989), the relation between alexithymia and locus of control has been studied. Using one of the more widely applied locus of control scales (IPC, the Internal Powerful Others Chance Scale; Levenson, 1973, 1974), Loas, Dhee-Perot, Gayant, and Fremaux (1996) showed that TAS-26 scores correlated negatively with Internal scores $(r=-.18)$ in a sample of 132 healthy subjects. Recently, Verissimo, Taylor, and Bagby (2000) found that alexithymia assessed by the TAS-20 correlates positively with both Powerful others scores $(r=.35)$ and Chance scores $(r=.23)$, while it correlates negatively with Internal scores $(r=-.25)$. These results are not surprising as, on one hand, we know that the external locus is positively associated with a series of negative psychological traits that one could label as general neuroticism, and, on the other hand, the internal locus is most strongly related to active coping and dominance (Brosschot, Gebhardt, \& Godaert, 1994).

The aim of this study was to compare the TAS-26 and the TAS-20 and to explore relations between alexithymia and personality, especially aspects that have not been taken into account so far such as irrational beliefs and impulsiveness.

Since Ellis and Harper (1961) suggested that irrational beliefs are a prime cause of emotional maladjustment, there has been considerable research interest in the relations between cognitive and emotional processes. Koopermans, Sanderman, Timmerman, and Emmelkamp (1994, p. 15) defined irrational beliefs as unrealistic "rea- 
soning processes by which external events are interpreted and through which emotional distress is mediated." As alexithymia reflects a deficit in the cognitive processing and regulation of emotional states, we hypothesized that alexithymia is related to irrational beliefs.

There are several reasons to postulate a correlation between alexithymia and impulsivity. Given that alexithymia is conceptualized as a disorder of emotion regulation (Taylor, 1994), some authors suggested that alexithymic individuals tend to discharge tension resulting from disagreeable emotional states through impulsive acts (Keltikangas-Jarvinen, 1982; Kroner \& Forth, 1995; Zimmermann, submitted) or compulsive behaviors such as substance abuse (Krystal \& Raskin, 1970; Haviland, Hendryx, Shaw, \& Henry, 1994), or eating disorders (Corcos, Guilbaud, Speranza, Paterniti, Loas, Stephan, \& Jeammet, 2000). Consequently, we hypothesized a correlation between impulsivity and alexithymia.

Thus, we studied the differential associations between alexithymia (assessed by TAS-26 and TAS-20) and the FFM, locus of control, impulsiveness, and irrational beliefs.

\section{Method}

\section{Subjects}

The study sample consisted of 286 undergraduate students (96 men, 190 women) from the University of Lausanne in Switzerland. The mean age of the sample was 21.90 years (range 18 to $57 / S D=5.20$ ). One hundred and thirty-six (26 men, 110 women) participants completed the items of the TAS-26 and the TAS-20, the Malouff and Schutte Belief Scale, the $\mathrm{I}_{7}$ Questionnaire, the IPC, and the NEO PI-R in a period of two weeks. The other 150 completed only the items of the TAS-20 and the TAS-26. Our study is in compliance with the ethical code of the Swiss Federation of Psychology (FSP).

\section{Measures}

Alexithymia was measured with two versions of the most reliable and validated self-report questionnaire: the 26-item (Taylor, Ryan, \& Bagby, 1985) and the 20-item

Table 1. TAS-20 rotated factor matrix. Item loadings below I.20I are not reported and item loadings above I.50I are in italics.

\begin{tabular}{|c|c|c|c|c|}
\hline \multirow{2}{*}{ Items } & & \multicolumn{3}{|c|}{ Factors } \\
\hline & & I & II & III \\
\hline \multicolumn{5}{|c|}{ Difficulty Describing Feelings } \\
\hline 1. & I am often confused about what emotion I am feeling & .50 & .37 & \\
\hline 2. & It is difficult for me to find the right words for my feelings & .74 & & \\
\hline 4. ${ }^{\mathrm{a}}$ & I am able to describe my feelings easily & .75 & & \\
\hline 9. & I have feelings that I can't quite identify & .65 & .37 & \\
\hline 11. & I find it hard to describe how I feel about people & .62 & .23 & \\
\hline 12. & People tell me to describe my feelings more & .64 & & \\
\hline 13. & I don't know what's going on inside me & .50 & .45 & \\
\hline 17. & It's difficult for me to reveal my innermost feelings, even to close friends & .59 & & \\
\hline \multicolumn{5}{|c|}{ Difficulty Identifying Feelings } \\
\hline 3. & I have physical sensations that even doctors don't understand & & .61 & \\
\hline 6. & When I am upset, I don't know if I am sad, frightened, or angry & .39 & .40 & \\
\hline 7. & I am often puzzled by sensations in my body & & .72 & \\
\hline $10 .^{\mathrm{a}}$ & Being in touch with emotions is essential & .27 & .38 & .25 \\
\hline 14. & I often don't know why I am angry & & .56 & .22 \\
\hline \multicolumn{5}{|c|}{ Externally Oriented Thinking } \\
\hline $5 .^{\mathrm{a}}$ & I prefer to analyse problems rather than just describe them & & & .39 \\
\hline 8. & I prefer to just let things happen rather than to understand why they turned out that way & & & .37 \\
\hline 15. & I prefer talking to people about their daily activities rather than their feelings & & & .59 \\
\hline 16. & I prefer to watch "light" entertainment shows rather than psychological dramas & & & .59 \\
\hline $18 .^{\mathrm{a}}$ & I can feel close to someone, even in moments of silence & & & .37 \\
\hline 19. ${ }^{\mathrm{a}}$ & I find examination of my feelings useful in solving personal problems & .21 & -.26 & .32 \\
\hline 20. & Looking for hidden meanings in movies or plays distracts from their enjoyment & & & .62 \\
\hline
\end{tabular}

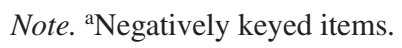


Toronto Alexithymia Scales (Bagby et al., 1994a,b). French-language validated versions were used (Loas, Fremaux, Marchand, Chaperot, \& Dardennes, 1993; Loas, Fremaux, \& Marchand, 1995). Factor analyses have previously suggested that the TAS-26 has a four factor structure (Taylor et al., 1985) and that the TAS-20 has a three factor structure (Parker, Bagby, Taylor, Endler, \& Schmitz, 1993). These structures are theoretically in accordance with the alexithymia construct. Item responses are rated on a 5-point Likert scale ranging from 1 (complete disagreement) to 5 (complete agreement).

The FFM was measured with the French-language version of the revised NEO PI-R developed by Costa and Mc Crae (1992; Rolland \& Petot, 1997; Rossier, Wenger, $\&$ Berthoud, 2001). This 240-item questionnaire was designed to assess the five domains of FFM, each made of six facets (see Table 4). Neuroticism (N) assesses affective emotional instability vs. adjustment. Extraversion (E) assesses the quantity and intensity of interpersonal interactions, the need for stimulation, and the capacity to experience joy. Openness to experience $(\mathrm{O})$ is defined as the proactive seeking and appreciation of various experiences for their own sake and as toleration for and exploration of the unfamiliar. As Extraversion evaluates the degree to which an individual enjoys being in the presence of others, Agreeableness (A) examines the attitude a person holds toward other people. Conscientiousness (C) assesses the individual's degree of organization, persistence, and motivation in goal-directed behavior. Item responses are rated on a 5-point Likert format ranging from 1 (strongly disagree) to 5 (strongly agree).

Locus of control was rated using the French-language validated version of the IPC (Levenson, 1973; Loas, Dardennes, Dhee-Perot, Leclerc, \& Fremaux, 1994; Rossier, Rigozzi, \& Berthoud, 2002). Levenson differentiated between three sources of control, one internal (I) and two external ones ( $\mathrm{P}$ and $\mathrm{C}$ ). The Levenson scales measure the degree to which people believe that life outcomes are controlled by each of these three sources: (1) their own actions or characteristics (I), (2) powerful others (P) and (3) chance or fate $(C)$. Each of the three scales consists of eight items presented in a 6-point Likert format ranging from -3 (strongly disagree) to +3 (strongly agree).

Impulsiveness was assessed with the validated French version of the $\mathrm{I}_{7}$ Impulsiveness Questionnaire (Eysenck, Pearson, Easting, \& Allsopp, 1985; Bouvard, 1999; Zimmermann, Rossier, \& Meyer de Stadelhofen, 2004). The Eysencks (1978) suggested that there are two main factors in Impulsiveness, which are distinct and aligned with different aspects of personality. On the one hand, Impulsiveness is characteristic of "people who act on the spur of the moment without being aware of any risk involved"; on the other hand, Venturesomeness is characteristic of "people who are well aware of the risks they might run but are prepared to chance it" (Eysenck, Easting, \& Pearson, 1984, pp. 315). In addition to these two factors, Empathy is a control dimension unrelated to the others, characteristic of people able to identify with others. This instrument consists of 54 self-report true/false items.

Irrational Beliefs were assessed with the French validated version of the Malouff and Schutte Belief Scale (Malouff \& Schutte, 1986; Freeston \& Ladouceur, 1993). Ellis and Harper (1961) postulated that irrational beliefs are a prime cause of emotional maladjustment. This scale consists of 20 self-reported statements (2 items for each of 10 irrational beliefs postulated by Ellis and Harper) presented in a 5-point Likert format ranging from 1 (strongly disagree) to 5 (strongly agree). Typical items are "To be a worthwhile person I must be thoroughly competent in everything I do," or "Life should be easier than it is."

\section{Statistical Analyses}

Means and standard deviations for the TAS-26 and the TAS-20 were calculated. Factorial analyses were conducted on both versions of the TAS to check their structural validity. Pearson correlations were used to assess the relations between the TAS-20 scores and the TAS-26 scores, as well as between these scores and the scores on the other scales. Because these personality variables are known to be intercorrelated, we performed stepwise multiple regression analyses. We alternatively used the TAS-26 and the TAS-20 scores as dependent variables and other scales as independent variables. Stepwise multiple regressions examined the influence of personality dimensions on TAS-26 and TAS-20 scores. Finally, facets scores of the NEO PI-R were entered in stepwise analyses to predict TAS-26 and TAS-20 scores.

\section{Results}

The TAS-26 and TAS-20 mean scores are respectively $62.00(S D=10.88)$ and $46.00(S D=10.08)$. These results are comparable to what Loas et al. $(1993,1996)$ found in French samples. In our sample, respectively, $60.3 \%$ and $41.2 \%$ of the subjects are below the cutoff scores for alexithymia (64 for TAS-26 and 44 for TAS-20) and, respectively, $14 \%$ and $13.2 \%$ are above it ( 73 for TAS-26 and 56 for TAS-20). TAS-26 and TAS-20 scores correlate strongly $(r=.90, p<.001)$.

Structural validity of the TAS-20 is satisfactory (see Table 1). Indeed, the three factor solution, explaining $37.6 \%$ of the variance, extracted through principal com- 
Table 2. TAS-26 rotated factor matrix. Item loadings below I.20I are not reported and item loadings above I.50| are in italics.

\begin{tabular}{|c|c|c|c|c|c|}
\hline \multirow{2}{*}{ Items } & & \multirow[b]{2}{*}{$\mathbf{I}$} & \multicolumn{2}{|c|}{ Factors } & \multirow[b]{2}{*}{ IV } \\
\hline & & & II & III & \\
\hline \multicolumn{6}{|c|}{ Difficulty to Identify and to Distinguish between Feelings and Bodily Sensations } \\
\hline $1 .^{\mathrm{a}}$ & When I cry I always know why & .48 & & & \\
\hline 4. & I am often confused about what emotion I am feeling & .61 & & & \\
\hline 8. & It is difficult for me to find the right words for my feelings & .71 & & & \\
\hline 10. & I have physical sensations that even doctors don't understand & .48 & & & -.45 \\
\hline 12. ${ }^{\mathrm{a}}$ & I am able to describe my feelings easily & .65 & & & .23 \\
\hline 14. & When I am upset, I don't know if I am sad, frightened, or angry & .54 & & & \\
\hline 20. & I have feelings that I can't quite identify & .74 & & & \\
\hline 22. & I find it hard to describe how I feel about people & .64 & & & \\
\hline 23. & People tell me to describe my feelings more & .50 & & & .21 \\
\hline 25. & I don't know what's going on inside me & .64 & & & \\
\hline 26. & I often don't know why I am angry & .44 & & & -.21 \\
\hline \multicolumn{6}{|c|}{ Reduced Daydreaming } \\
\hline 2. & Daydreaming is a waste of time & & .52 & & \\
\hline $5 .{ }^{\mathrm{a}}$ & I often daydream about the future & & .72 & & \\
\hline $15 .^{\mathrm{a}}$ & I use my imagination a great deal & & .54 & & .37 \\
\hline $16 .^{\mathrm{a}}$ & I spend much time daydreaming whenever I have nothing else to do & -.25 & .74 & & \\
\hline 18. & I daydream rarely & & .75 & & \\
\hline \multicolumn{6}{|c|}{ Externally Oriented Thinking } \\
\hline 7. & Knowing the answers to problems is more important than knowing the reasons for the answers & & & .50 & -.33 \\
\hline $11 .^{\mathrm{a}}$ & It's not enough for me that something gets the job done; I need to know why and how it works & & & .67 & \\
\hline $13 .^{\mathrm{a}}$ & I prefer to analyse problems rather than just to describe them & & & .56 & \\
\hline 19. & I prefer just let things happen rather than to understand why they turned out that way & & & .59 & \\
\hline $24 .^{\mathrm{a}}$ & One should look for deeper explanations & & & .69 & \\
\hline \multicolumn{6}{|c|}{ Difficulty Describing Feelings } \\
\hline 3. & I wish I were not so shy & .30 & & & .40 \\
\hline $6 .^{\mathrm{a}}$ & I seem to make friends as easily as others do & .21 & & & .52 \\
\hline $9 .^{a}$ & I like to let people know where I stand on things & & & & .61 \\
\hline 17. & I am often puzzled by sensations in my body & .43 & & & -.44 \\
\hline 21. & Being in touch with emotions is essential & & & & .36 \\
\hline
\end{tabular}

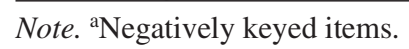

ponents analysis, followed by a varimax rotation, is in accordance with the initial three factor structure (Bagby et al., 1994). Factor 1, which accounts for $20.4 \%$ of the variance, correlates strongly $(r=.94, p<.001)$ with the DDF subscale (Difficulty Describing Feelings), and is mainly composed of the five items of the DDF factor and three items of the DIF subscale (Difficulty Identifying Feelings). Factor 2, which accounts for $10 \%$ of the variance, correlates strongly $(r=.81, p<.001)$ with the DIF subscale and is mainly composed of the remaining items of the DIF factor. Factor 3, which accounts for $7.2 \%$ of the variance, correlates strongly $(r=.95, p<.001)$ with the EOT subscale (Externally Oriented Thinking) and is mainly composed of the eight items of the EOT subscale. The TAS-20 demonstrates a good internal consistency $(\alpha=.75)$.

Structural validity of the TAS-26 seems to be satisfac-
Table 3. Correlations between the factors of the TAS-20 and the TAS-26.

\begin{tabular}{llll}
\hline & & $\begin{array}{r}\text { TAS-20 } \\
\text { Factor 2 }\end{array}$ & Factor 3 \\
\hline TAS-26 & & & \\
Factor 1 & $.82^{* * *}$ & $.55^{* * *}$ & .01 \\
Factor 2 & .08 & $-.20^{* *}$ & .09 \\
Factor 3 & .05 & -.01 & $.40 * * *$ \\
Factor 4 & $.35^{* * *}$ & $-.55^{* * *}$ & .06 \\
\hline
\end{tabular}

$* p<.05, * * p<.01, * * * p<.001$.

tory (see Table 2). The four factor solution, explaining $40.6 \%$ of the variance, is in accordance with the initial four factor structure (Taylor et al., 1985). Factor 1, representing $17.5 \%$ of the variance, correlates strongly ( $r=$ 
Table 4. TAS-20 and TAS-26 correlations with NEO PI-R, IPC, $\mathrm{I}_{7}$, and Belief Scale.

\begin{tabular}{|c|c|c|c|c|c|c|c|c|c|}
\hline & \multicolumn{4}{|c|}{ TAS-20 } & \multicolumn{5}{|c|}{ TAS-26 } \\
\hline & DIF & DDF & EOT & Total & DIFDF & DDF & RD & EOT & Total \\
\hline \multicolumn{10}{|l|}{ NEO PI-R } \\
\hline Neuroticism & $.52 * * *$ & $.28 * *$ & .06 & $.44 * * *$ & $.52 * * *$ & $.35 * * *$ & -.16 & .16 & $.45^{* * *}$ \\
\hline Anxiety & $.42 * * *$ & $-.29 * *$ & .04 & $.36 * * *$ & $.43 * * *$ & $.31 * *$ & -.09 & .07 & $.35 * * *$ \\
\hline Angry Hostility & $.36^{* * *}$ & -.14 & -.00 & $.26 * *$ & $.35 * * *$ & $.19^{*}$ & -.08 & .02 & $.27 * * *$ \\
\hline Depression & $.47 * * *$ & $.19^{*}$ & .03 & $.37 * * *$ & $.44 * * *$ & $.28 * *$ & -.12 & .10 & $.39 * * *$ \\
\hline Self-Consciousness & $.44 * * *$ & $.26^{* *}$ & .07 & $.39 * * *$ & $.44 * * *$ & $.39 * * *$ & $-.17 *$ & .10 & $.40 * * *$ \\
\hline Impulsiveness & $.21 *$ & .01 & .03 & $.19^{*}$ & $.22 * *$ & .08 & -.17 & $.22 *$ & $.17 *$ \\
\hline Vulnerability & $.52 * * *$ & $.30 * * *$ & .14 & $.49 * * *$ & $.52 * *$ & $.36 * * *$ & -.11 & $.26^{* *}$ & $.50 * * *$ \\
\hline Extraversion & -.01 & -.15 & -.15 & $-.19 *$ & -.13 & $-.30 * * *$ & .00 & -.05 & $-.23 * *$ \\
\hline Warmth & -.09 & -.13 & -.20 & $-.19 *$ & -.11 & $-.21 *$ & .04 & $-.20 *$ & $-.21 *$ \\
\hline Gregariousness & .01 & -.00 & -.00 & -.01 & .01 & -.08 & .03 & .08 & -.01 \\
\hline Assertiveness & $-.26 * *$ & $-.26 * *$ & -.13 & $-.32 * * *$ & $-.30 * * *$ & $-.42 * * *$ & -.02 & -.12 & $-.39 * * *$ \\
\hline Activity & -.07 & -.11 & -.11 & -.15 & -.11 & $-.19 *$ & .12 & -.03 & -.12 \\
\hline Excitement-Seeking & .15 & .07 & -.05 & .11 & .13 & -.03 & .01 & .07 & .10 \\
\hline Positive Emotions & -.12 & -.16 & -.13 & $-.19 *$ & -.13 & $-.25 * *$ & -.14 & -.05 & $-.26 * *$ \\
\hline Openness & .04 & -.14 & $-.25 * *$ & -.13 & -.03 & $-.21 *$ & $-.24 * *$ & $-.21 *$ & $-.21 *$ \\
\hline Fantasy & .03 & -.07 & -.08 & -.05 & -.03 & -.13 & $-.54 * * *$ & .07 & $-.21 *$ \\
\hline Aesthetics & $.17 *$ & .11 & $-.18 *$ & .08 & $.19 *$ & .06 & -.16 & $-.21 *$ & .01 \\
\hline Feelings & .11 & $-.21 *$ & $-.18 *$ & -.12 & .01 & $-.23 * *$ & -.11 & -.15 & -.14 \\
\hline Actions & -.08 & -.17 & -.13 & -.16 & -.10 & $-.22 *$ & -.02 & -.09 & -.16 \\
\hline Ideas & -.05 & -.08 & $-.25 * *$ & -.12 & -.08 & -.14 & -.04 & $-.28 * *$ & -.17 \\
\hline Values & -.05 & $-.19 *$ & -.09 & -.16 & -.11 & $-.19 *$ & .01 & -.10 & -.14 \\
\hline Agreeableness & -.03 & .06 & .07 & .04 & .00 & .08 & .11 & -.09 & .04 \\
\hline Trust & -.10 & -.11 & -.03 & -.08 & -.13 & -.13 & .07 & -.00 & -.09 \\
\hline Straightforwardness & -.03 & .07 & .05 & .04 & .02 & .11 & .07 & -.08 & -.04 \\
\hline Altruism & -.09 & -.06 & -.07 & -.11 & -.07 & $-.17 *$ & -.01 & -.17 & $-.17 *$ \\
\hline Compliance & .03 & .10 & .07 & .08 & .05 & $.19^{*}$ & -.01 & -.11 & .06 \\
\hline Modesty & .04 & $.19 *$ & .14 & .16 & .12 & $.20^{*}$ & $.22 *$ & .04 & $.21 *$ \\
\hline Tender Mindedness & .05 & .00 & .02 & .04 & .05 & .03 & .06 & -.06 & .04 \\
\hline Conscientiousness & -.13 & -.06 & -.10 & -.16 & -.14 & -.09 & $.17 *$ & $-.36 * * *$ & $-.18^{*}$ \\
\hline Competence & $-.19 *$ & -.14 & -.09 & $-.22 * *$ & $-.20 *$ & -.13 & .14 & $-.35 * * *$ & $-.23 * *$ \\
\hline Order & .05 & .03 & -.06 & -.01 & .04 & .04 & .11 & $-.20 *$ & .00 \\
\hline Dutifulness & -.03 & .01 & -.03 & -.05 & -.02 & -.00 & .16 & -.15 & -.04 \\
\hline Achievement Striving & -.04 & -.05 & -.09 & -.11 & .07 & .12 & .00 & $.36 * * *$ & $-.20 *$ \\
\hline Self-Discipline & $-.25 * *$ & -.06 & -.10 & $-.22 *$ & $-.24 * *$ & -.14 & $.25 * *$ & $-.29 * *$ & $-.22 * *$ \\
\hline Deliberation & -.12 & -.05 & -.08 & -.11 & -.12 & -.04 & .11 & $-.26 * *$ & -.12 \\
\hline \multicolumn{10}{|l|}{$I P C$} \\
\hline Internal & -.12 & -.14 & -.13 & $-.18^{*}$ & $-.18^{*}$ & $-.20 *$ & -.03 & $-.18^{*}$ & $-.24 *$ \\
\hline Powerful Others & $.24 * *$ & $.22 *$ & $.18^{*}$ & $.31 * * *$ & $.25^{* *}$ & $.26 * *$ & -.09 & $.22 *$ & $.29 * * *$ \\
\hline Chances & $.30 * * *$ & $.21 *$ & $.28 * *$ & $.40 * * *$ & $.32 * *$ & $.18^{*}$ & -.08 & $.25 * *$ & $.33 * * *$ \\
\hline \multicolumn{10}{|l|}{$I_{7}$} \\
\hline Impulsiveness & $.20 *$ & .11 & -.08 & .15 & $.19^{*}$ & .05 & -.08 & .14 & .15 \\
\hline Venturesomeness & -.07 & -.08 & -.07 & -.08 & -.10 & -.14 & .05 & -.08 & -.10 \\
\hline Empathy & $.26 * *$ & .15 & -.13 & .15 & $.25 * *$ & $.20 *$ & -.16 & -.10 & .13 \\
\hline Belief Scale & $.37 * * *$ & $.24 * *$ & -.01 & $.34 * * *$ & $.37 * * *$ & $.26 * *$ & $-.20 *$ & .04 & $.29 * * *$ \\
\hline
\end{tabular}

Note. DIF = Difficulty Identifying Feelings; DDF = Difficulty Describing Feelings; EOT = Externally Oriented Thinking; DIFDF = Difficulty Identifying Feelings and Distinguishing Feelings and Bodily Sensations; RD = Reduced Daydreaming.

$* p<.05, * * p<.01, * * * p<.001$. 
Table 5. Stepwise regression analyses predicting TAS-20 and TAS-26 scores from Belief Scale, $\mathrm{I}_{7}$, IPC and NEO PI-R domains scores.

\begin{tabular}{|c|c|c|c|c|c|}
\hline & $\beta$ & $R^{2}$ & $\begin{array}{l}\text { Adjusted } \\
R^{2}\end{array}$ & $\begin{array}{l}F \\
\text { change }\end{array}$ & $p$ \\
\hline \multicolumn{6}{|l|}{ TAS-20 } \\
\hline $\begin{array}{l}\text { NEO-PI-R } \\
\text { Neuroticism }\end{array}$ & $.325 * * *$ & .194 & .188 & 32.196 & .000 \\
\hline IPC Chances & $.255^{* * * *}$ & .245 & .234 & 9.119 & .003 \\
\hline \multicolumn{6}{|l|}{ TAS-26 } \\
\hline $\begin{array}{l}\text { NEO-PI-R } \\
\text { Neuroticism }\end{array}$ & $.434 * * *$ & .201 & .195 & 33.804 & .000 \\
\hline $\begin{array}{l}\text { NEO-PI-R } \\
\text { Openness }\end{array}$ & $-.172 *$ & .231 & .219 & 5.072 & .026 \\
\hline
\end{tabular}

$.98, p<.001$ ) with the first initial factor (Difficulty to Identify and to Distinguish between Feelings and Bodily Sensations), and is mainly composed of the 11 items of this factor and 1 item of the factor reflecting the ability to communicate feelings. Factor 2, accounting for $9.5 \%$ of the variance, correlates strongly $(r=.97, p<.001)$ with the third initial factor (Reduced Daydreaming), and is mainly composed of the five items of this factor. Factor 3 , which accounts for $7.1 \%$ of the variance, correlates strongly $(r=.95, p<.001)$ with the fourth initial factor (Externally Oriented Thinking), and is mainly composed of five of the six items of this factor. Factor 4 accounts for $6.5 \%$ of the variance and correlates moderately $(r=$ $.51, p<.001$ ) with the second initial factor (Difficulty Describing Feelings), and is mainly composed of three of the seven items of this factor. The TAS-26 demonstrates a good internal consistency $(\alpha=.72)$.

The Pearson correlations between the three factor solution of the TAS-20 and the four factor solution of the TAS-26 are reported in Table 3.

Table 4 displays Pearson correlations between Toronto Alexithymia Scales on the one hand and NEO PI-R domains and facets, IPC, $\mathrm{I}_{7}$, Malouff and Schutte Belief Scales on the other hand. Correlations indicate that the TAS-26 and TAS-20 scores correlate significantly and positively with scores on the Belief Scale, IPC Powerful Others, and Chance scales, NEO PI-R Neuroticism, and NEO PI-R Neuroticism facets N1 (Anxiety), N2 (Angry Hostility), N3 (Depression), N4 (Self-Consciousness), N5 (Impulsiveness), and N6 (Vulnerability). Significant negative correlations are obtained with scores on the IPC Internal scale, NEO PI-R Extraversion, NEO PI-R Extraversion facets E1 (Warmth), E3 (Assertiveness), E6 (Positive Emotions), and NEO PI-R Conscientiousness facets C1 (Competence) and C5 (Self-Discipline). Others significant correlations are found between the TAS26 and the NEO PI-R domains Openness and Conscien-
Table 6. Stepwise regression analyses predicting TAS-20 and TAS-26 scores from NEO PI-R facets scores.

\begin{tabular}{|c|c|c|c|c|c|}
\hline & $\boldsymbol{\beta}$ & $R^{2}$ & $\begin{array}{l}\text { Adjust- } \\
\text { ed } R^{2}\end{array}$ & $\begin{array}{l}F \\
\text { change } \\
\end{array}$ & $p$ \\
\hline \multicolumn{6}{|l|}{ TAS-20 } \\
\hline $\begin{array}{l}\text { Vulnerability } \\
\text { (N6) }\end{array}$ & $.500 * * *$ & .235 & .230 & 41.262 & .000 \\
\hline $\begin{array}{l}\text { Excitement- } \\
\text { Seeking (E5) }\end{array}$ & $.187^{*}$ & .265 & .255 & 5.527 & .020 \\
\hline Feelings (O3) & $-.233 * *$ & .290 & .274 & 4.518 & .035 \\
\hline \multicolumn{6}{|l|}{ TAS-26 } \\
\hline $\begin{array}{l}\text { Vulnerability } \\
\text { (N6) }\end{array}$ & $.420 * * *$ & .251 & .246 & 44.989 & .000 \\
\hline Fantasy (O1) & $-.189^{*}$ & .302 & .292 & 9.743 & .002 \\
\hline $\begin{array}{l}\text { Excitement- } \\
\text { Seeking (E5) }\end{array}$ & $.237 * *$ & .331 & .317 & 5.857 & .017 \\
\hline Feelings (O3) & $-.182 *$ & .356 & .338 & 5.237 & .024 \\
\hline $\begin{array}{l}\text { Assertive- } \\
\text { ness (E3) }\end{array}$ & $-.205^{*}$ & .378 & .354 & 4.107 & .045 \\
\hline
\end{tabular}

tiousness and the NEO PI-R facets O1 (Fantasy), A3 (A1truism), A5 (Modesty), and C4 (Achievement Striving).

More specifically, the DIF factor of the TAS-20 and the DIDF factor of the TAS-26 present relatively high positive significant correlations with scores on the NEO PI-R Neuroticism domain and NEO PI-R Neuroticism facets N1 (Anxiety), N3 (Depression), N4 (Self-Consciousness), and N6 (Vulnerability). Other high negative significant correlations are respectively found between the DDF factor and the RD factor of the TAS-26 and the NEO PI-R facets E3 (Assertiveness) and O1 (Fantasy).

Regression analyses (see Table 5) show that $24.5 \%$ of the variance of the TAS-20 can be explained by NEO PI-R Neuroticism and IPC Chance, while $23.1 \%$ of the variance of the TAS-26 can be accounted for by two domains of the NEO PI-R: Neuroticism and Openness. At the facet level of the NEO PI-R (see Table 6), Vulnerability (N6), Excitement-Seeking (E5), and Feelings (O3) are found to be the only significant predictors of TAS-20 scores whereas Vulnerability (N6), Fantasy (O1), Excitement-Seeking (E5), Feelings (O3), and Assertiveness (E3) are found to be the only predictors of TAS-26 scores.

\section{Discussion}

The overall results of this study indicate that, on one hand, alexithymia is associated positively with Neuroticism, external Locus of Control, and Irrational Beliefs and, on the other hand, that alexithymia is associated 
negatively with Extraversion and internal Locus of control. These findings are close to what previous studies found (Bagby et al., 1994b; Luminet et al., 1999; Verissimo et al., 2000) and congruent with clinical observations of alexithymic patients (McDougall, 1982; Taylor et al., 1997).

Contrary to previous studies (Haviland et al., 1988; Haviland \& Reise, 1996; Loas et al., 1993, 1996), the factorial structures of the TAS-26 and the TAS-20 are not as unstable as expected. Nevertheless, our data suggest that the items of the TAS-26 and the TAS-20 assessing difficulty in identifying feelings and difficulty in describing feelings may constitute a single factor, although recent studies conducting confirmatory factor analyses showed the superiority of the three factor initial solutions for the TAS-20 (Taylor, Bagby, \& Luminet, 2000).

When we examine the relations between alexithymia and the FFM, the findings could constitute an indication that alexithymia, especially when using TAS-20, is similar to the construct of Neuroticism, as some authors have suggested (Mayer, DiPaolo, \& Salovey, 1990; Rubino, Grasso, Sonnino, \& Pezzarossa, 1991). The results of our regression analyses suggest that the TAS-20 may be a measure of general distress rather than one of a lack of introspective ability. Furthermore, the TAS-26 may be a measure of general distress and limited range of interests.

However, as Luminet et al. (1999) suggested, the findings become more refined and interesting when we consider the relations between alexithymia and the facets of FFM. Consistent with previous studies (Bagby et al., 1994b; Luminet et al., 1999), alexithymia is positively associated with a tendency to experience anxiety, anger, depressive affects, and feelings of shame and embarrassment. Alexithymia is also positively associated with the inability to cope with stressful situations. These results are consistent with the conception of Lane and Schwartz (1987) who consider that alexithymic individuals are prone to experience undifferentiated unpleasant emotional arousal as they avoid reflecting on and generating symbolic representations of experience. Regression analyses show that the Vulnerability facet is the only facet of Neuroticism that significantly predicts TAS-26 and TAS-20 scores. This finding is consistent with the view that alexithymia is not an adaptative defence or coping style against affective distress associated with stressful situations (Parker, Taylor, \& Bagby, 1998).

Within the domain of Extraversion, alexithymia is associated negatively and most strongly with the Assertiveness facet but is also associated with the facets of Warmth and Positive Emotions. Surprisingly, regression analyses indicate that the Excitement-Seeking facet is the only facet of Extraversion that significantly predicts TAS-20 scores and that Excitement-Seeking and Assertiveness are both predictors of the TAS-26 scores. Contrary to
Bagby et al. (1994b) and Luminet et al. (1999), we do not find a strong negative relation between alexithymia and the tendency to experience positive emotions, but our findings are consistent with clinical descriptions that emphasize a reduced need for interpersonal relations and stimulation in alexithymic individuals (Apfel \& Sifneos, 1979).

Surprisingly and contrary to previous studies (Bagby et al., 1994b; Luminet et al., 1999), TAS-20 scores are unrelated to the domain of Openness to Experience and its facets. TAS-26 scores, on the other hand, are negatively associated with Openness to Experience and its facet Fantasy. However, regression analyses at facet level indicate that a low score on the Feelings facet predicts TAS-20 scores and that a low score on the Fantasy and Feelings facets predicts TAS-26 scores. As expected, the Fantasy facet is retained as a predictor of the TAS-26 but not as a predictor of the TAS-20. Therefore, these results suggest that the TAS-26 allows a more multifaceted assessment of the alexithymia construct. The lack of receptivity to one's own inner feelings is a central feature of alexithymia assessed by the TAS-20 and the TAS-26, whereas paucity of imagination and of fantasy life, one of the main characteristics of the initial alexithymia construct (Nemiah et al., 1976), is an important feature assessed by the TAS- 26 .

Although alexithymia is unrelated to the Agreeableness domain, at a facet level TAS-26 scores are negatively associated with Altruism and positively associated with Modesty. The negative relation with altruism suggests that high scorers on the TAS-26 are somewhat more self-centered and are reluctant to get involved in the problems of others, consistent with clinical observations (McDougall, 1989) and empirical evidence that alexithymic individuals manifest a limited capacity for empathy (Parker, Taylor, \& Bagby, 2001). The positive relation with modesty indicates that alexithymia is associated with humility and perhaps with a lack of self-confidence or self-esteem (Piedmont, 1998).

Finally, as found in earlier studies (Bagby et al., 1994; Luminet et al., 1999) TAS-20 scores are unrelated to the Conscientiousness domain. In this study, however, TAS26 scores are negatively associated with Conscientiousness, and at the facet level TAS-20 scores are negatively associated with Competence and TAS-26 scores with Competence and Self-Discipline. According to Costa and McCrae (1992), the Competence facet is the most highly associated with self-esteem, and the Self-Discipline facet is associated with self-control and motivation. These relations suggest that alexithymic individuals have a lower opinion of their abilities and a lack of motivation to complete their projects.

When we consider the relation between alexithymia and locus of control, our results confirm expectations 
based on theoretical and empirical grounds (Brosschot et al., 1994; Verissimo et al., 2000). These relations are consistent with clinical observations of the utilitarian mode of thinking and living of alexithymic individuals (Marty \& Debray, 1989). Furthermore, Brosschot et al. (1994) showed that (1) internal locus of control is associated with active coping and positive evaluation of life events, that (2) powerful others locus of control is associated with passive coping and hostile feelings, and that (3) chance locus of control is associated with psychopathological problems. These results confirm the role of alexithymia in coping with stress and in health behavior, and reinforce the view that alexithymia is linked to maladaptive coping strategies (Parker et al., 1998).

Surprisingly, in our normal population there is no significant association between alexithymia and impulsiveness even if the NEO PI-R Impulsiveness facet has a low correlation with TAS-26 and TAS-20 scores. As a recent study demonstrated, it might be more informative to examine the alexithymia subscales rather than the global alexithymia score (Deary, Scott, \& Wilson, 1997). Thus, we observe that TAS-20 DIF and TAS-26 DIFDF correlate positively with Impulsiveness. This suggests that difficulty in identifying feelings is the only important trait related to impulsiveness; this corresponds to the sensorimotor enactive level of the model of Lane and Schwartz (1987). At this level, the ability to experience emotion as a conscious feeling state has not developed and the aim of action tendencies is to maximize pleasure or to minimize distress (Lane \& Schwartz, 1987).

Finally, the positive relations obtained between alexithymia and irrational beliefs are consistent with the view that alexithymia reflects an emotional maladjustment and a risk factor for somatic and psychological disorders (Taylor et al., 1997). As cognitive belief systems play an important role in mediating emotional distress, irrational beliefs promote unrealistic reasoning processes by which external events are misinterpreted and emotional distress is mediated (Koopermans et al., 1994). According to Ellis (1962), irrational beliefs lead to dysfunctional consequences like somatic or psychological symptoms. Some studies suggest that irrational beliefs mediate attempts to cope with perceived stressors (Harran \& Ziegler, 1991), and consequently irrational beliefs like alexithymia are conceptualized as a vulnerability factor to stress.

These results extend previous studies and support the relevance of alexithymia as a valid personality construct. Although, as expected, alexithymia overlaps with various dimensions of the FFM, as well as other dimensions like external Locus of Control and Irrational Beliefs, these variables explain only a portion of the variance. Alexithymia appears to be a cognitive state of externally oriented thinking with an emotional instability associat- ed to the inability to cope with stressful situations. Despite the absence of items directly assessing fantasy life in the TAS-20, TAS-26 scores and TAS-20 scores are strongly associated. Contrary to what Taylor et al. (2000) suggested, the externally oriented thinking factor of the TAS-20 does not adequately assess the impoverished inner fantasy life component. Therefore, the use of the TAS-26 to assess alexithymia, as it was initially conceptualized, seems advisable. Use of either scales can be recommended even if the TAS- 20 is currently the most widely used and reliable measure of the alexithymia construct. Future research must be directed toward examining the explanatory power of alexithymia and its subscales as a unique construct not redundant with existing dimensions of personality.

\section{References}

Apfel, R.J., \& Sifneos, P.E. (1979). Alexithymia: Concept and measurement. Psychotherapy and Psychosomatics, 32, 180-190.

Bagby, R.M., Parker, J.D.A., \& Taylor, G.J. (1994a). The TwentyItem Toronto Alexithymia Scale - I. Item selection and cross validation of the factor structure. Journal of Psychosomatic Research, 38, 23-32.

Bagby, R.M., Taylor, G.J., \& Parker, J.D.A. (1994b). The Twenty-Item Toronto Alexithymia Scale II. Convergent discriminant, and concurrent validity. Journal of Psychosomatic Research, 38, 33-40.

Bagby, R.M., Taylor, G.J., Parker, J.D.A., \& Loiselle, C. (1990). Cross-validation of the factor structure of the Toronto Alexithymia Scale. Journal of Psychosomatic Research, 34, 47-51.

Bouvard, M. (1999). Questionnaires et échelles d'évaluation de la personnalité [Personality scales and questionnaires]. Paris: Masson.

Bressi, C., Taylor, G., Parker, J., Bressi, S., Brambilla, V., Aguglia, E., Allegranti, I., Bongiorno, A., Giberti, F., Bucca, M., Todarello, O., Callegari, C., Vender, S., Gala, C., \& Invernizzi, G. (1996). Cross validation of the factor structure of the 20-item Toronto Alexithymia Scale: An Italian multicenter study. Journal of Psychosomatic Research, 41, 551-559.

Brosschot, J.F., Winifried, A.G., \& Godaert, G.L.R. (1994). Internal, powerful others, and chance locus of control: Relationship with personality, coping, stress, and health. Personality and Individual Differences, 16, 839-852.

Corcos, M., Guilbaud, O., Speranza, M., Paterniti, S., Loas, G., Stephan, Ph., \& Jeammet, Ph. (2000). Alexithymia and depression in eating disorders. Psychiatry Research, 93, 263-266.

Costa, P.T., \& McCrae, R.R. (1985). The NEO personality manual. Odessa, FL: Psychological Assessment Resources.

Costa, P.T., \& McCrae, R.R. (1987). Personality assessment in psychosomatic medicine. Advances in Psychosomatic medicine, 17, 71-82.

Costa, P.T., \& McCrae, R.R. (1992). NEO Personality Inventory Revised (NEO PI-R) and NEO Five-Factor Inventory (NEOFFI) professional manual. Odessa, FL: Psychological Assessment Resources. 
Digman, J.M. (1990). Personality structure: Emergence of the five-factor model. Annual Review of Psychology, 41, 417-440.

Ellis, A. (1962). Reason and emotion in psychotherapy. New York: Lyle-Stuart.

Ellis, A., \& Harper, R.A. (1961). A guide to rational living. Englewood Cliffs, NJ: Prentice-Hall.

Eysenck, S.B.G., Easting, G., \& Pearson, P.R. (1984). Age norms for impulsiveness, venturesomeness, and empathy in children. Personality and Individual Differences, 5, 315-321.

Eysenck, S.B.G., \& Eysenck, H.J. (1978). Impulsiveness and Venturesomeness: Their position in a dimensional system of personality description. Psychological Reports, 43, 1247-1255.

Eysenck, S.B.G., Pearson, P.R., Easting, G., \& Allsopp, J.F. (1985). Age norms for impulsiveness, venturesomeness, and empathy in adults. Personality and Individual Differences, 6, 613-619.

Freeston, M.H., \& Ladouceur, R. (1993). Appraisal of cognitive intrusions and response style: Replication and extension. $B e-$ havior Research \& Therapy, 31, 185-191.

Harran, S., \& Ziegler, D. (1991). Cognitive appraisal of daily hassles in college students displaying high and low irrational beliefs. Journal of Rational Emotive and Cognitive Behavior Therapy, 9, 265-271.

Haviland, M.G., Hendryx, M.S., Shaw, D.G., \& Henry, J.P. (1994). Alexithymia in women and men hospitalized for psychoactive substance dependence. Comprehensive Psychiatry, 35, 124-128.

Haviland, M.G., \& Reise, S.P. (1996). Structure of the twenty-item Toronto Alexithymia Scale. Journal of Personality Assessment, 66, 116-125.

Haviland, M.G., Shaw, D.G., Cummings, M.A., \& MacMurray, J.P. (1988). Alexithymia: Subscales and relationship to depression. Psychotherapy and Psychosomatics, 50, 164-170.

Keltikangas-Jarvinen, L. (1982). Alexithymia in violent offenders. Journal of Personality Assessment, 46, 462-467.

Koopermans, P.C., Sanderman, R., Timmerman, I., \& Emmelkamp, P.M.G. (1994). The Irrational Beliefs Inventory (IBI): Development and psychometric evaluation. European Journal of Psychological Assessment, 10, 15-27.

Kroner, D.G., \& Forth, A.E. (1995). The Toronto Alexithymia Scale with incarcerated offenders. Personality and Individual Differences, 19, 625-634.

Krystal, H. (1988). Integration and self healing: Affect, trauma, alexithymia. Hillsdale, NJ: Analytic Press.

Krystal, H., \& Raskin, H. (1970). Drug dependence. Detroit: Wayne State University Press.

Lane, R.D., \& Schwartz, G.E. (1987). Level of emotional awareness: A cognitive-developmental theory and its application to psychopathology. American Journal of Psychiatry, 144, 133143.

Levenson, H. (1973). Multidimensional locus of control in psychiatric patients. Journal of Consulting and Clinical Psychology, 41, 397-404.

Levenson, H. (1974). Activism and powerful others: Distinction within the concept of internal-external control. Journal of Personality Assessment, 38, 377-383.

Loas, G., Dardennes, R., Dhee-Perot, P., Leclerc, V., \& Fremaux, D. (1994). Opérationnalisation du concept de "lieu de contrôle": Traduction et première étude de validation de l'échelle de contrôle de Levenson (IPC: The internal powerful others and chance scale) [Operationalization of the "locus of control" concept: Translation and first validation study of the Levenson Control Scale (IPC: The internal and powerful others and chance scale)]. Annales Médico-Psychologiques, 152, 466469.

Loas, G., Dhee-Perot, P., Gayant, C., \& Fremaux, D. (1996). Alexithymia and locus of control. Perceptual and Motor Skills, 82, 14.

Loas, G., Fremaux, D., \& Marchand M.P. (1995). Etude de la structure factorielle et de la cohérence interne de la version française de l'échelle d'alexithymie de Toronto à 20 items (TAS-20) chez un groupe de 183 sujets sains [Factorial structure and internal consistency of the French version of the 20item Toronto Alexithymia Scale in a group of 183 healthy probands]. L'Encéphale, 21, 117-122.

Loas, G., Fremaux, D., Marchand, M.P., Chaperot, C., \& Dardennes, R. (1993). L'alexithymie chez le sujet sain: Validation de l'échelle d'alexithymie de Toronto (TAS) dans une population "tout venant" de 144 sujets, application au calcul de prévalence [Alexithymia in sane persons: Validation of the Toronto Alesithymia Scale]. Annales Médico-Psychologiques, 151, 660-663.

Loas, G., Otmani, O., Verrier, A., Fremaux, D., \& Marchand, M.P. (1996). Factor analysis of the French version of the 20-item Toronto Alexithymia Scale (TAS-20). Psychopathology, 29, 139-144.

Luminet, O., Bagby, R.M., Wagner, H., Taylor, G.J., \& Parker, J.D.A. (1999). Relation between alexithymia and the five-factor model of personality: A facet level analysis. Journal of Personality Assessment, 73, 345-358.

Malouff, J.M., \& Schutte, N.S. (1986). Development and validation of a measure of irrational belief. Journal of Consulting and Clinical Psychology, 54, 860-862.

Marty, P., \& Debray, R. (1989). Current concepts of character disturbances. In S. Cheren (Ed.), Psychosomatic medicine: Theory, physiology, and practice (pp. 159-184). Madison, CT: International Universities Press.

Mayer, J.D., DiPaolo, M., \& Salovey, P. (1990). Perceiving affective content in ambiguous visual stimuli: A component of emotional intelligence. Journal of Personality Assessment, 54, 772-781.

McDougall, J. (1982). Alexithymia: A psychoanalytic viewpoint. Psychotherapy \& Psychosomatics, 38, 81-90.

McDougall, J. (1989). Theater of the body: A psychoanalytic approach to psychosomatic illness. New York: Norton.

Marty, P., \& de M'Uzan, M. (1963). La 'pensée opératoire' [Operative thinking]. Revue Française de Psychanalyse, 27 (Suppl.), 1345-1356.

Nemiah, J.C., Freyberger, H., \& Sifneos, P.E. (1976). Alexithymia: A view of the psychosomatic process. In O.W. Hill (Ed.), Modern trends in psychosomatic medicine (Vol. 3, pp. 430439). London: Butterworths.

Nemiah, J.C., \& Sifneos, P.E. (1970). Affect and fantasy in patients with psychosomatic disorders. In O.W. Hill (Ed.), Modern trends in psychosomatic medicine (vol. 2, pp. 26-34). London: Butterworths.

Parker, J.D.A., Bagby, R.M., Taylor, G.J., Endler, N.S., \& Schmitz, P. (1993). Factorial validity of the 20-item Toronto Alexithymia Scale. European Journal of personality, 7, 221232.

Parker, J.D.A., Taylor, G.J., \& Bagby, R.M. (1998). Alexithymia: 
Relationship with ego defence and coping styles. Comprehensive Psychiatry, 39, 91-98.

Parker, J.D.A., Taylor, G.J., \& Bagby, R.M. (2001). The relationship between emotional intelligence and alexithymia. Personality and individual differences, 30, 107-115.

Pandey, R., Mandal, M.K., Taylor, G.J., \& Parker, J.D.A. (1996). Cross-cultural alexithymia: Development and validation of a Hindi translation of the 20-item Toronto Alexithymia Scale. Journal of Clinical Psychology, 52, 173-176.

Piedmont, R.L. (1998). The revised NEO Personality Inventory, clinical and research applications. New York: Plenum Press.

Roland, J-P., \& Petot, J-M. (1997). Manuel de la version française $d u$ NEO PI-R [French NEO PI-R manual]. Paris: Editions du Center de Psychologie Appliquée.

Rossier, J., Rigozzi, C., \& Berthoud, S. (2002). Validation de la version française de l'échelle de contrôle de Levenson (IPC), influence de variables démographiques et de la personnalité [Validation of the French translation of Levenson's locus of control scale (IPC). Influence of demographic variables and personality]. Annales Médico-Psychologiques, 160, 138-148.

Rossier, J., Wenger, S., \& Berthoud, S. (2001). Validation interne de la version française du NEO PI-R et influence de l'âge, du sexe et de la profession [Internal validation of the French version of the NEO PI-R and impact of age, gender, and profession]. Psychologie et Psychométrie, 22, 59-79.

Rubino, I.A., Grasso, S., Sonnino, A., \& Pezzarossa, B. (1991). Is alexithymia a nonneurotic personality dimension? British Journal of Medical Psychology, 64, 385-391.

Sifneos, P.E. (1973). The prevalence of "alexithymic" characteristics in psychosomatic patients. Psychotherapy and Psychosomatics, 22, 255-262.

Sifneos, P.E. (1996). Alexithymia: Past and present. American Journal of Psychiatry, 153(Suppl. 7), 137-142.

Sifneos, P.E. (2000). Alexithymia, clinical issues, politics, and crime. Psychotherapy and Psychosomatics, 69, 113-116.

Taylor, G.J. (1994). The alexithymia construct: Conceptualization, validation, and relationship with basic dimensions of personality. New Trends in Experimental and Clinical Psychiatry, $10,61-74$.

Taylor, G.J., Bagby, R.M., \& Luminet, O. (2000). Assessment of alexithymia: Self-report and observer-rated measures. In J.D.A. Parker \& R. Bar-On (Eds.), The handbook of emotional intelligence (pp. 301-319). San Francisco, CA: Jossey Bass.
Taylor, G.J., Bagby, R.M., \& Parker, J.D.A. (1992). The Revised Toronto Alexithymia Scale: Some reliability, validity, and normative data. Psychotherapy \& Psychosomatics, 57, 34-41.

Taylor, G.J., Bagby, R.M., \& Parker, J.D.A. (1997). Disorders of affect regulation. Alexithymia in medical and psychiatric illness. Cambridge, England: Cambridge University Press.

Taylor, G.J., Ryan, D., \& Bagby, R.M. (1985). Toward the development of a new self-report alexithymia scale. Psychotherapy \& Psychosomatics, 44, 191-199.

Verissimo, R., Taylor, G.J., \& Bagby, R.M. (2000). Relationship between alexithymia and locus of control. New Trends in Experimental and Clinical Psychiatry, 16, 11-16.

Wise, T.N., Mann, L.S., \& Shay, L. (1992). Alexithymia and the five-factor model of personality. Comprehensive Psychiatry, $33,147-151$.

Whiteside, S.P., \& Lynam, D.R. (2001). The Five Factor Model and impulsivity: Using a structural model of personality to understand impulsivity. Personality and Individual Differences, 30, 669-689.

Zimmermann, G. (submitted). Delinquency in male adolescents: The role of alexithymia. Journal of Adolescence.

Zimmermann, G., Rossier, J., \& Meyer de Stadelhofen, F. (2004). Validation de la version française du questionnaire I7 d'impulsivité. Influence de la personnalité, du sexe et de la religion [Validation of the French version of Eysenck's impulsiveness questionnaire $\left(\mathrm{I}_{7}\right)$. Influence of personality, gender, and religion]. Annales Médico-Psychologiques, 162, 116-121.

Address for correspondence

Grégoire Zimmermann

Department of Psychology

University of Lausanne

BFSH 2 - Dorigny

CH-1015 Lausanne

Switzerland

Tel. +41 21 692-3260

Fax +41 21 692-3265

E-mail Gregoire.Zimmermann@unil.ch 